\title{
IMPLEMENTATION OF PANTANAL MAGNETIC OBSERVATORY IN BRAZIL
}

\author{
Fillipe Siqueira and Katia J. Pinheiro
}

\begin{abstract}
Magnetic observatories are fundamental to study different magnetic sources, measuring precisely and continuously the geomagnetic field. The largest restriction of the observatories is their uneven distribution on the Earth's surface, especially in South America, where only few data are available. In this work, we describe the main steps for the installation of the magnetic observatory in Pantanal Region (Brazil) and the data analysis of a magnetic station that registered the field from September 29th, 2011 up to January 25th, 2012. From the geomagnetic point of view, the installation of the magnetic observatory is interesting due to the occurrence of the South Atlantic Magnetic Anomaly (SAMA), which is the region with the smallest intensity of the geomagnetic field. The SAMA is generated by dynamical processes in the external core, but many unsolved questions concerning its temporal evolution and its causes still remain. This anomaly causes effects in the external field: during magnetic storms there may be problems in satellites, navigation systems and radio-communication. These disturbances more often occur in areas where the intensity of the field is smaller (as in the case of SAMA) or larger (as at the poles). The data generated by the Pantanal observatory will contribute to a better understanding of SAMA and its effects in the external magnetic field.
\end{abstract}

Keywords: geomagnetism, magnetic observatories, magnetic storms.

RESUMO. Observatórios magnéticos são fundamentais para garantir um registro preciso e contínuo do campo magnético da Terra. A maior limitação dos observatórios é a distribuição desigual na superfície terrestre, principalmente na América do Sul, onde há poucos dados. Neste trabalho descrevemos as principais etapas executadas para a instalação do observatório magnético no Pantanal e a análise de dados de uma estação magnética, que registrou o campo do dia 29 de setembro de 2011 até 25 de janeiro de 2012. A instalação do observatório magnético do Pantanal é interessante, do ponto de vista geomagnético, devido à presença da Anomalia Magnética do Atlântico Sul (AMAS), que é a região de menor intensidade do campo magnético no globo. A AMAS é gerada por processos dinâmicos no núcleo externo, mas ainda há muitas questões em aberto sobre sua evolução temporal e suas causas. A AMAS também pode causar efeitos no campo externo: durante as tempestades podem ocorrer problemas em satélites, sistemas de navegação e radiocomunicação. Estes distúrbios ocorrem mais frequentemente nas áreas onde a intensidade do campo é menor (como é o caso da AMAS) ou maior (nos polos). Os dados gerados no observatório do Pantanal contribuirão para uma melhor compreensão sobre a AMAS e seus efeitos no campo externo.

Palavras-chave: geomagnetismo, observatórios magnéticos, tempestades magnéticas. 


\section{INTRODUCTION}

The Earth's magnetic field is measured by magnetic observatories, magnetic repeat stations and surveys. The main part of the observed field comes from the Earth's core. It is caused by the geodynamo process (Roberts, 2007), where the field is generated by the convection of the low viscosity metalic fluid in the Earth's outer core. The crustal field and external field (magnetosphere and ionosphere) are two other magnetic sources.

Magnetic observatories are fixed locations measuring continuously, accurately the temporal variations of the internal and external magnetic fields for a long periods. Nevertheless, the distribution of observatories on the Earth's surface is still uneven (Fig. 1). In Brazil there are three magnetic observatories constructed and mantained by Observatório Nacional: Vassouras (Rio de Janeiro), Tatuoca (Pará) and Pantanal (PNL) magnetic observatory, located in the Mato Grosso state. Only Vassouras magnetic observatory is part of INTERMAGNET (the global network of magnetic observatories). The installation of Pantanal magnetic observatory, in October 2012, represents a significant improvement on data distribution in the central region of Brazil (Fig. 1).

Vassouras is the closest magnetic observatory from Pantanal, more than $1400 \mathrm{~km}$ distance (Table 1). In Brazil there are important geomagnetic phenomena, such as South Atlantic Magnetic Anomaly (SAMA) and Equatorial Electrojet. The small number of magnetic observatories in South America and their uneven distribution are common problems for the global analysis of the geomagnetic field.

Table 1 - Distance of magnetic observatories near Pantanal magnetic observatory.

\begin{tabular}{|c|c|}
\hline $\begin{array}{c}\text { Observatory } \\
\text { (Acronym) }\end{array}$ & $\begin{array}{c}\text { Distance from } \\
\text { Pantanal Observatory } \\
(\mathrm{km})\end{array}$ \\
\hline Vassouras (VSS) & 1456.12 \\
Huancayo (HUA) & 2125.07 \\
Kourou (KOU) & 2447.88 \\
Trelew (TRW) & 3071.05 \\
Port Stanley (PST) & 3883.44 \\
San Juan (SJG) & 3996.30 \\
Ascension Island (ASC) & 4632.80 \\
\hline
\end{tabular}

The SAMA is the region with the smallest intensity of the geomagnetic field in the Earth, causing an increase of input particles in this region (Heirtzler, 2002). These particles may damage equipments on satellites and on the Earth's surface. Pantanal magnetic observatory is near to the center of the SAMA (Hartmann \& Pacca, 2009).
During the installation of Pantanal observatory, a magnetic station (called PNL), recorded the total magnetic field (F) during four months. Two magnetic storms occurred in this period: the first on the 24th and 25th October 2011 and the second between 21st and 24th January 2012.

In this work we aim to (i) describe procedures of the installation of Pantanal magnetic observatory, following the methodology suggested by the IAGA (International Association of Geomagnetism and Aeronomy) and (ii) show preliminary results of the first PNL dataset.

\section{METHODOLOGY}

The method used for the installation of Pantanal magnetic observatory follows the methodology suggested by the IAGA (Jankowski \& Sucksdorff, 1996). The first step was to define a suitable place to install the observatory. In this case, the chosen Iocation was a private environmental reserve of SESC-Pantanal (Mato Grosso state). Ideally, a magnetic observatory should never change location in order to preserve a long time series. Thus, environmental reserves and military areas in Brazil are usually appropriated places. The selection of Pantanal observatory location was based on the preexisting infrastructure, such as electric power and internet connection.

Before installing Pantanal observatory we evaluated possible crustal anomalies in the region. We performed a gradiometer survey in a $35 \times 20$ meter area, with 1 meter intervals. Therefore, a gradiometer map was used to detect the best locations for installation of the variometer and absolute houses. We also tested all materials used in the house constructions by means of an overhauser gradiometer. For example, materials such as iron and rebars should never be used, because they cause strong interferences in the measurements. These tests were performed in the beginning of the day or at nightfall, when the geomagnetic field was quieter. In the process of Pantanal observatory installation, we recorded the total magnetic field in a magnetic station (PNL). The aim was to evaluate the quality of the data from this region and to compare with data from other observatories. The station measured the magnetic field during four months, when two magnetic storms were registered. We performed a wavelet analysis to determine the espectral content, the beginning and duration of the these magnetic storms.

\section{RESULTS AND DISCUSSION}

\section{The construction of Pantanal Magnetic Observatory}

After deciding about a possible location for Pantanal observatory, a gradiometer survey to detect possible magnetic anomalies was 


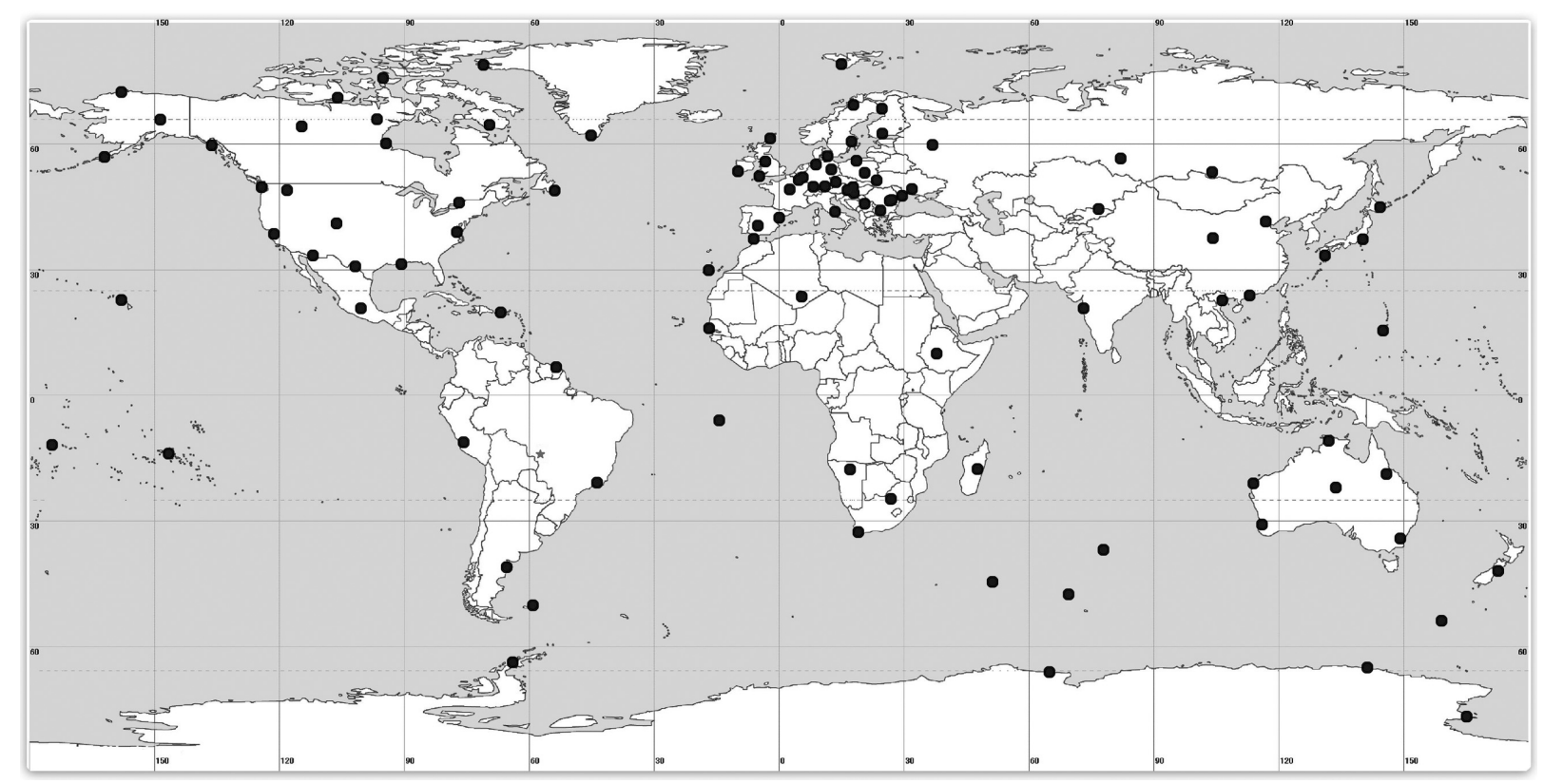

Figure 1 - INTERMAGNET observatories (black circles) and Pantanal magnetic observatory (gray star).

performed in a 35 meters by 20 meters area with one meter intervals. We used a GSM-19 overhauser gradiometer with a $56 \mathrm{~cm}$ distance between the sensors. The magnetic gradient in this region is very low, between $-3.75 \mathrm{nT} / \mathrm{m}$ and $2.35 \mathrm{nT} / \mathrm{m}$ (Fig. 2), with an average of $\pm 0.5 \mathrm{nT} / \mathrm{m}$. These values are in accordance with IAGA established patterns for the installation of magnetic observatories (Jankowski \& Sucksdorff, 1996), which defines up to $1 \mathrm{nT} / \mathrm{m}$ as an acceptable limit. In this study region there are two small magnetic anomalies: one in points $(11,6)$ and $(11,8)$ with -2.78 and $1.89 \mathrm{nT} / \mathrm{m}$ intensities, respectively, and the other in the points $(11,12)$ and $(11,14)$ with -1.68 and $2.53 \mathrm{nT} / \mathrm{m}$ intensities, respectively.

The cause of these magnetic anomalies was analyzed in a second fieldwork in the region. We found small peaces of iron some few centimeters below the soil. After removing these small pieces of wire (around 100 grams), new measurements of the magnetic gradient in the same area were performed (Fig. 3).

The small magnetic anomalies were still present, but their intensities decreased around $1 \mathrm{nT} / \mathrm{m}$ in comparison with the first gradient map. Even though this disturbance decreased, we avoided constructing the observatory buildings on these regions (Fig. 4).

All materials used in the construction of a magnetic observatory must be previously tested. We tested many materials, including plastic wood, stones, sand, sikal, concretion, cement and the resulting concrete from these material mixture.
Two tests were carried out: in the first, ten of the materials that would be used in the construction of the observatory were tested and, in the second, the ground used for the embankment in the places of the observatory buildings was analyzed.

In the first test, the plastic wood and all materials used in the foundations of the buildings were included (Fig. 5). The cement and the thin plastic wood were the materials that caused greater disturbances in the magnetic signal. The other materials did not cause any significant noise in the data $(-1 \mathrm{nT} \leq \Delta \mathrm{F} \leq+1 \mathrm{nT})$.

Figure 5 shows two peaks, one after the removal of the concrete from the equipment and the other during the laying of the concretion over the equipment, which were caused by the observer. A curiosity was that the concrete mixture done with the cement that caused magnetic disturbance did not present problems. This happens due to the change of the chemical properties of the cement when it was mixed with water, sand and crushed stone. Thus, there was no problem to use cement in the concrete mixture. The result of the second test was positive $(<0.5 \mathrm{nT})$ for the embankment and for the regional woods that were used ("aroeira" and "piúva").

\section{The magnetic station of Pantanal}

PNL data were obtained from 29th September 2011 until 25th January 2012, using the GSM-19 proton magnetometer. The geomagnetic field was registered at each 10 seconds but in order to simplify the comparison with other magnetic observatories we used 1 minute data (Fig. 6). 


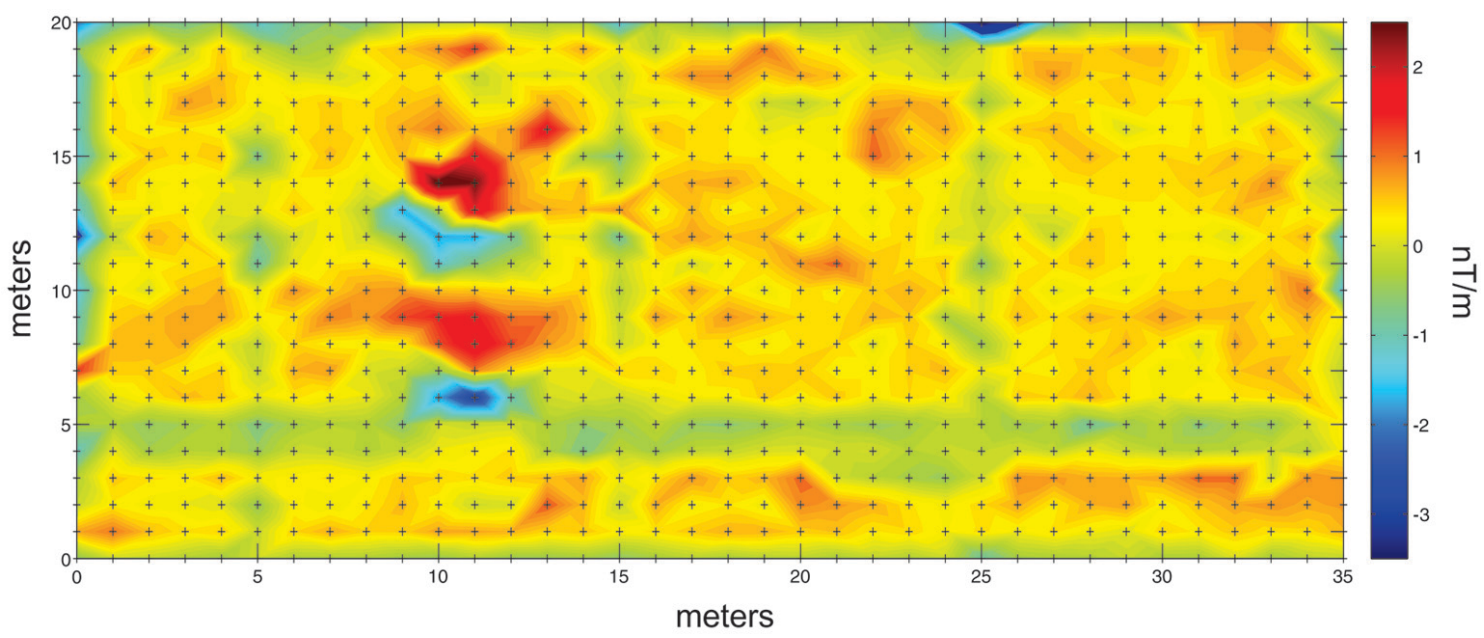

Figure 2 - Magnetic gradient of the chosen area for Pantanal magnetic observatory.



Figure 3 - Magnetic gradient of the chosen area after the removal of iron wire.

The total magnetic field $(\mathrm{F})$, during these four months, presented an average value of $23120 \mathrm{nT}$ (Fig. 7). The maximum recorded value was $23330 \mathrm{nT}$ and the minimum was $22900 \mathrm{nT}$.

The total magnetic field presented a disturbed behaviour in the region of Pantanal in two different periods. With the tracking of the geomagnetic indexes and the data from other observatories, it was confirmed that these two periods were equivalent to two geomagnetic storms. For simplicity, the storms were called $\mathrm{T} 1$ and T2 (Fig. 8), where T1 occurred from the 24th until the 25th October 2011 and T2 between 21st and 24th January 2012.

We compared PNL data with six magnetic observatories in the same range of latitude or longitude (Table 2), as shown in Figure 9. The variation range of the total magnetic field in PNL station was around $330 \mathrm{nT}$, while on average the other observatories presented smaller values of the order of $150 \mathrm{nT}$.
Table 2 - Geographic distribution of magnetic observatories used in this work. Source: INTERMAGNET.

\begin{tabular}{|c|c|c|}
\hline $\begin{array}{c}\text { Observatory } \\
\text { (Acronym) }\end{array}$ & $\begin{array}{c}\text { Colatitude } \\
\text { (Degrees) }\end{array}$ & $\begin{array}{c}\text { East longitude } \\
\text { (Degrees) }\end{array}$ \\
\hline Pantanal (PNL) & 106.68 & 303.82 \\
Ascension Island (ASC) & 97.95 & 345.62 \\
Kakadu (KDU) & 102.69 & 132.47 \\
Pamatai (PPT) & 107.57 & 210.42 \\
Port Stanley (PST) & 141.70 & 302.11 \\
San Juan (SJG) & 71.89 & 293.85 \\
St John's (STJ) & 42.40 & 307.32 \\
\hline
\end{tabular}

It is possible that the large variation of PNL station is the effect of the SAMA, while the high variation of the St John's observatory may be caused by its proximity to the Auroral Electrojet. As the 


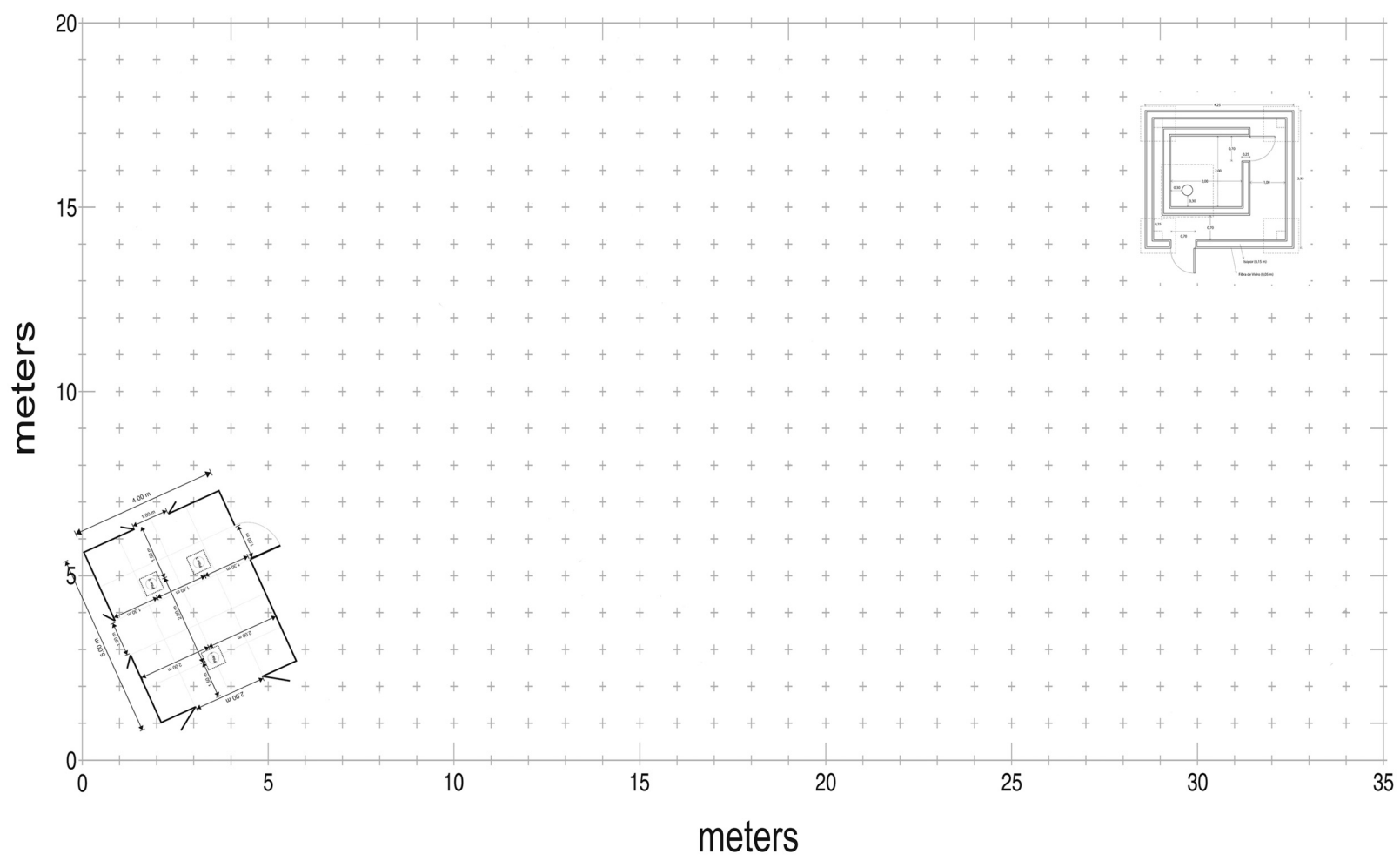

Figure 4 - Distribution of the buildings in Pantanal observatory. In the left bottom corner the absolute measurements building and near to the opposite vertex, the variometer building.
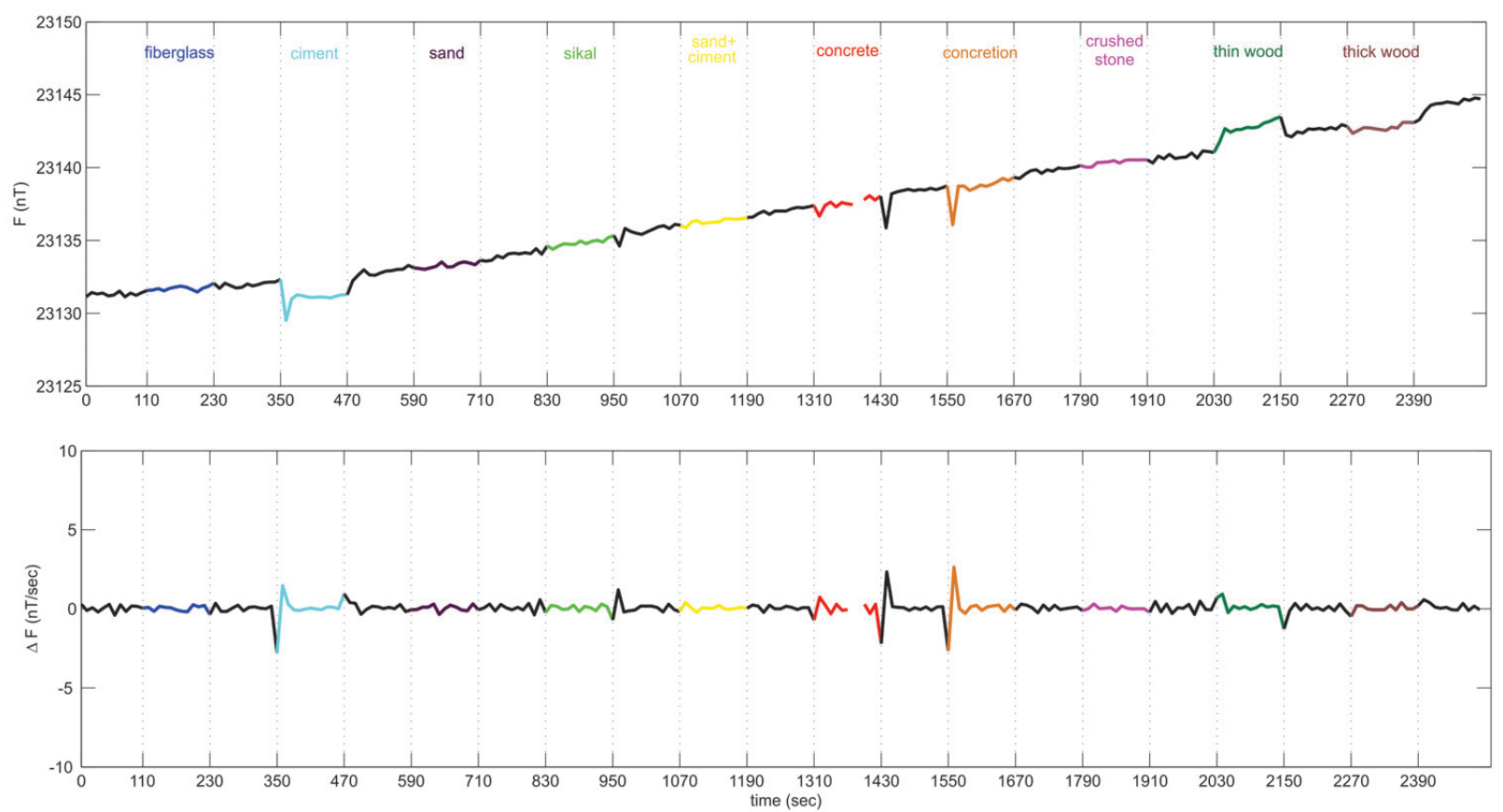

Figure $\mathbf{5}$ - Test with ten materials used to construct the buildings in Pantanal magnetic observatory. The natural magnetic field is showed among the tested materials marked in the chart. 


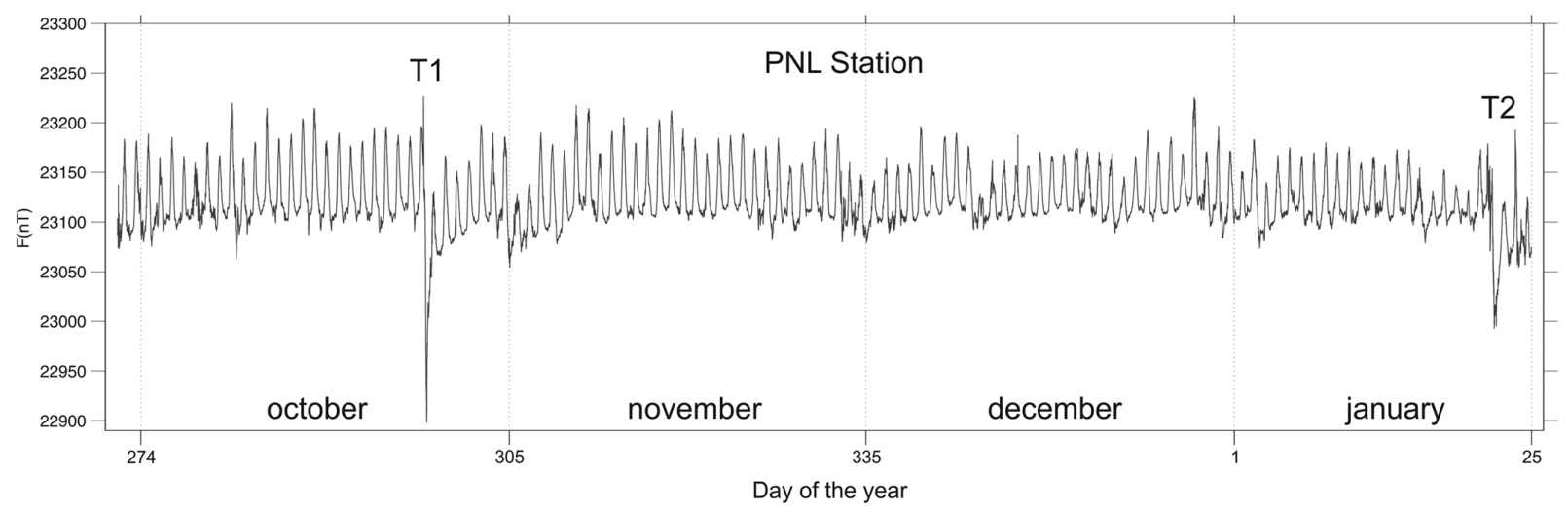

Figure 6 - Data from the 119 day period of Pantanal observatory measurements of the total geomagnetic field. T1 and T2 indicate the two storms that occurred during this period.

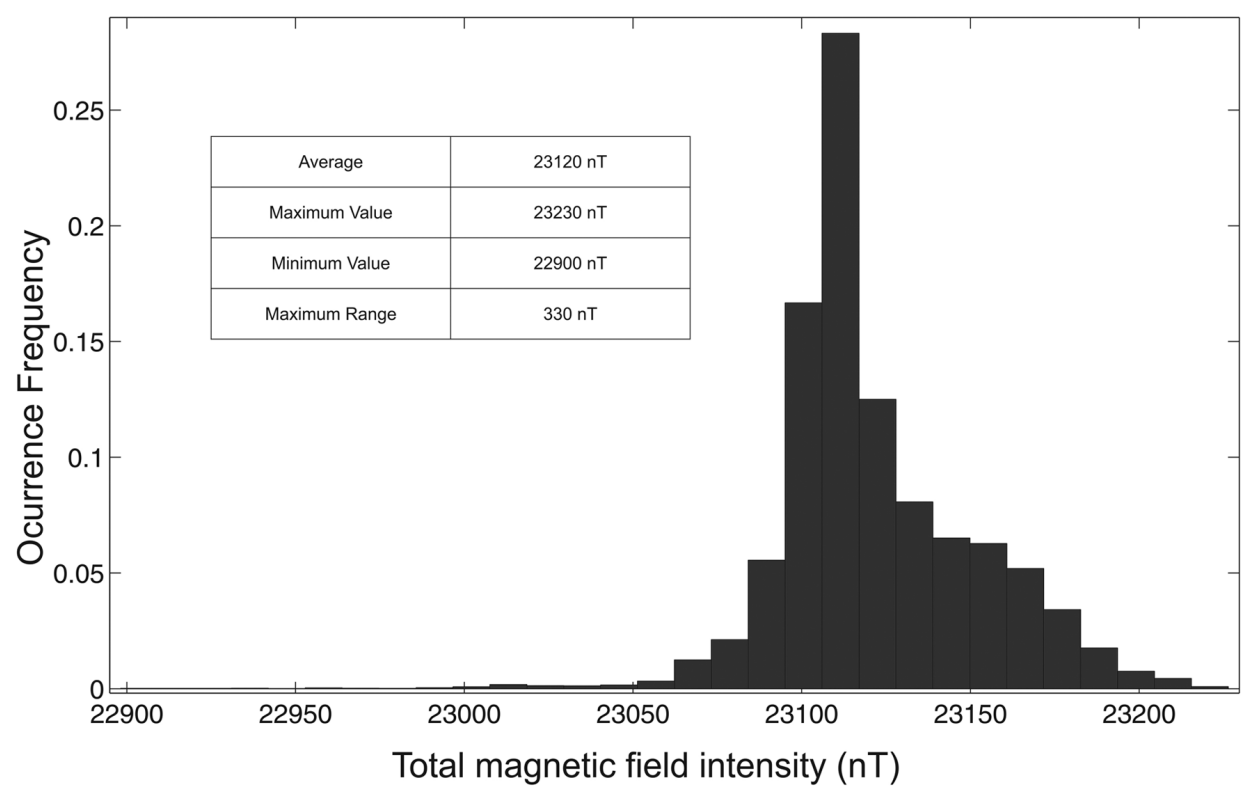

Figure 7 - Histogram with averages, maximum and minimum values reached in the dataset and the maximum variation.

SAMA represents a minimum in the magnetic field intensity, the region favors the incidence of space particles.

The usual behaviour of a magnetic storm is illustrated in Figure 10, starting with an increase of the magnetic field intensity, subsequently a strong decrease and after the field returns to the previous stable state. This storm was classified as $\mathrm{T} 1$ using the global indexes Kp and Dst (Fig. 11). The Dst index reaches the $-137 \mathrm{nT}$ minimum value in the first hours of the 25th day and the $\mathrm{Kp}$ index reached the $7+$ value in the beginning of the same day. The magnetic field reached its minimum value in the first hours of the 25th day and the sudden beginning occurred some hours before it. The same was observed in the six observatories analyzed in this work.
The wavelet transform is used to identify localised structures of the signal with a "zoom" procedure, by reducing the scale parameter. Singularities may be detected through the maximum local of the wavelet transform in small scales. We applied the 1-D wavelet transform ("coiflet3") of the MATLAB (Misiti et al., 1997) program interface in PNL station data.

The wavelet decomposition of $\mathrm{T} 1$ magnetic storm is shown in Figure 12. The $s$ curve represents the actual data, $a_{7}$ represents the decomposition for the lowest frequencies and $d_{1}$ to $d_{7}$ the decompositions for the highest frequencies. The beginning of the T1 magnetic storm was well marked in the wavelet decomposition for higher frequencies (from $d_{1}$ to $d_{7}$ ). However, the identification of the beginning of $\mathrm{T} 1$ magnetic storm was clearer from 



Figure 8 - Magnetic storms measured in the Pantanal magnetic station: T1, between 24th and 25th October 2011, and T2 between 21st and 24 th January 2012.

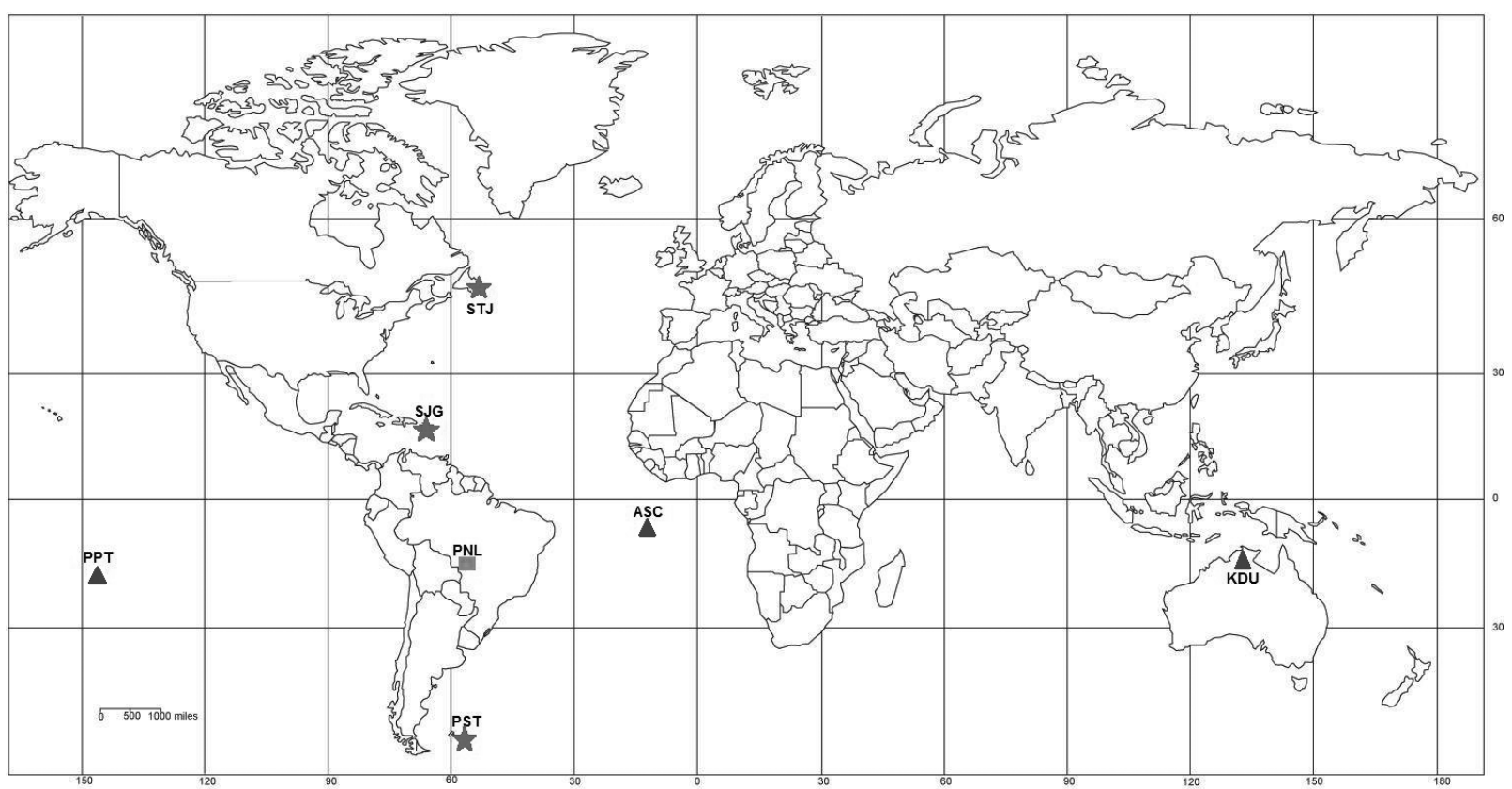

Figure 9 - Global distribution of magnetic observatories used in this study. Observatories in triangles present latitudes similar to the PNL (square) ones and observatories in stars present similar longitudes. 


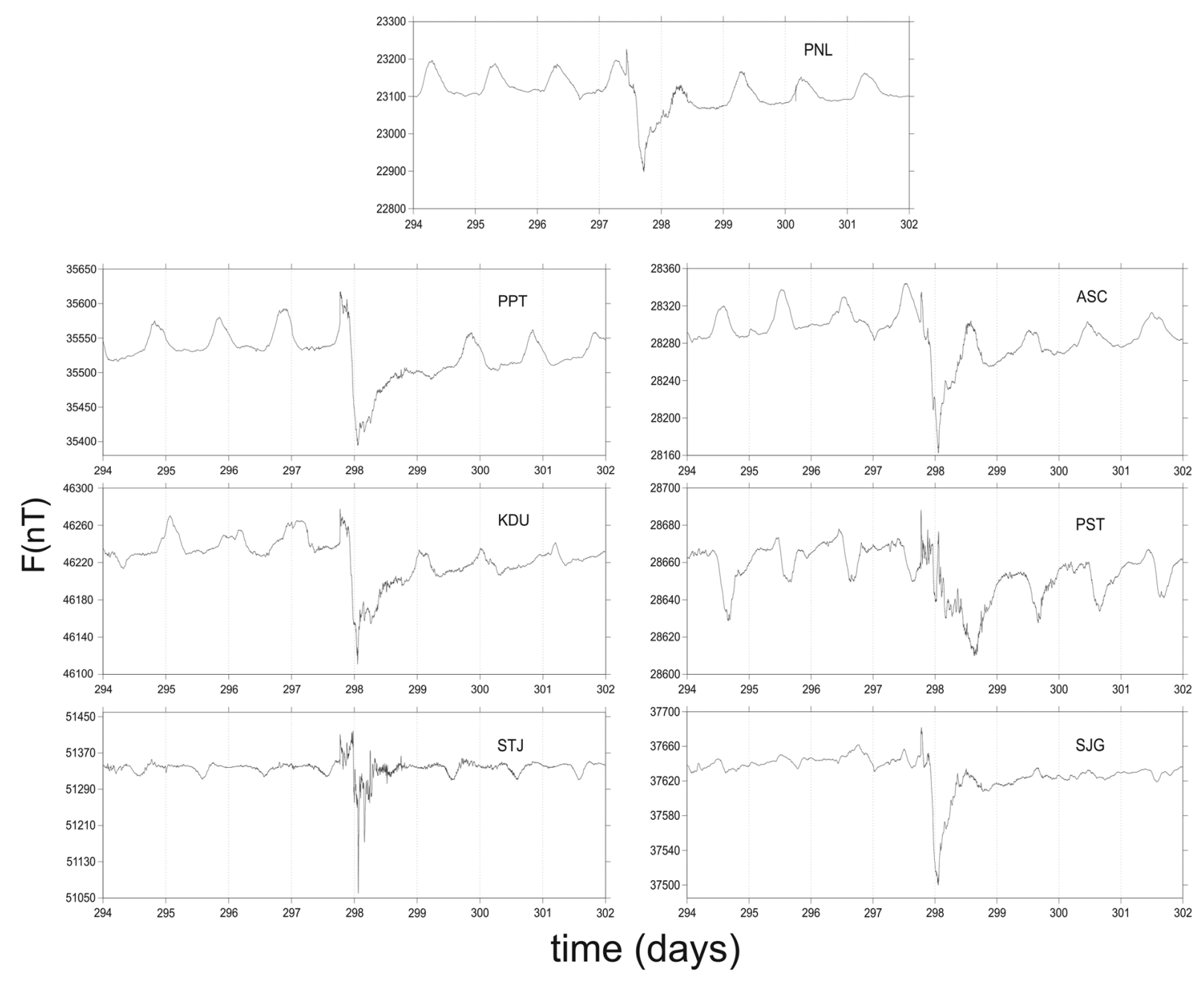

Figure 10 - T1 magnetic storm, between 24th and 25th October 2011, compared to observatories with latitudes (left column) and longitudes (right column) similar to Pantanal magnetic observatory.
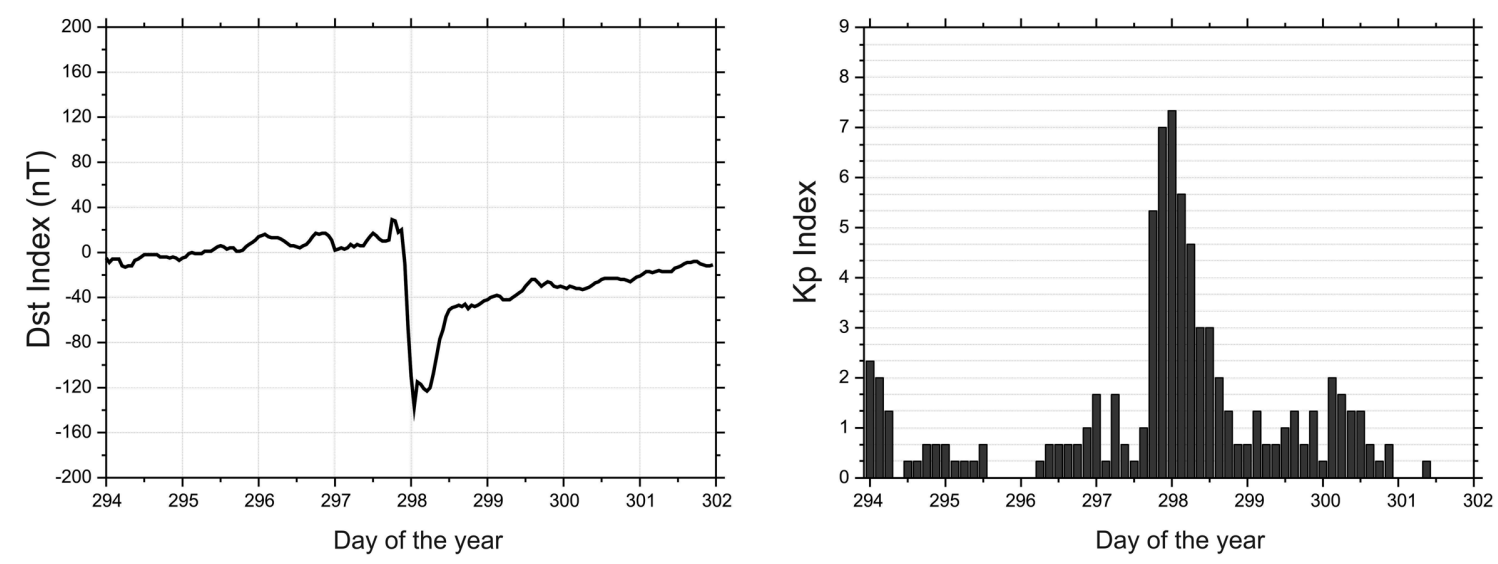

Figure 11 - Dst and Kp index variation during the T1 magnetic storm, between 24th and 25th October 2011. The left chart represents the Dst index (nT/time variation). The right shows the Kp index values in magnetic storm days. 


\section{PNL}

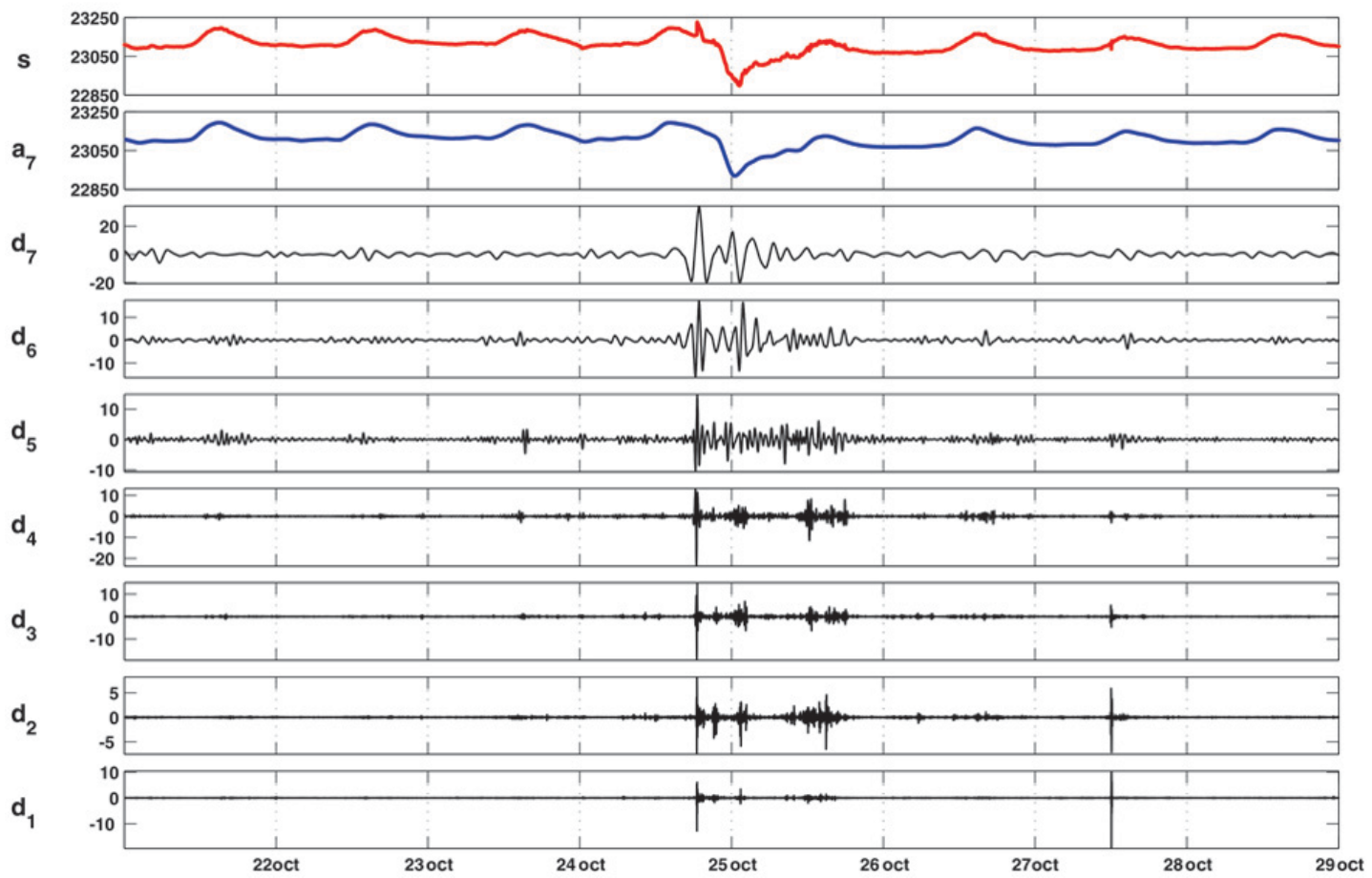

Figure 12 - Wavelet analysis of the T1 magnetic storm measured in PNL, where "s" represents the original data, $a_{7}$ is the decomposition for the lower frequencies and $d_{1-7}$ are decompositions for higher frequencies.

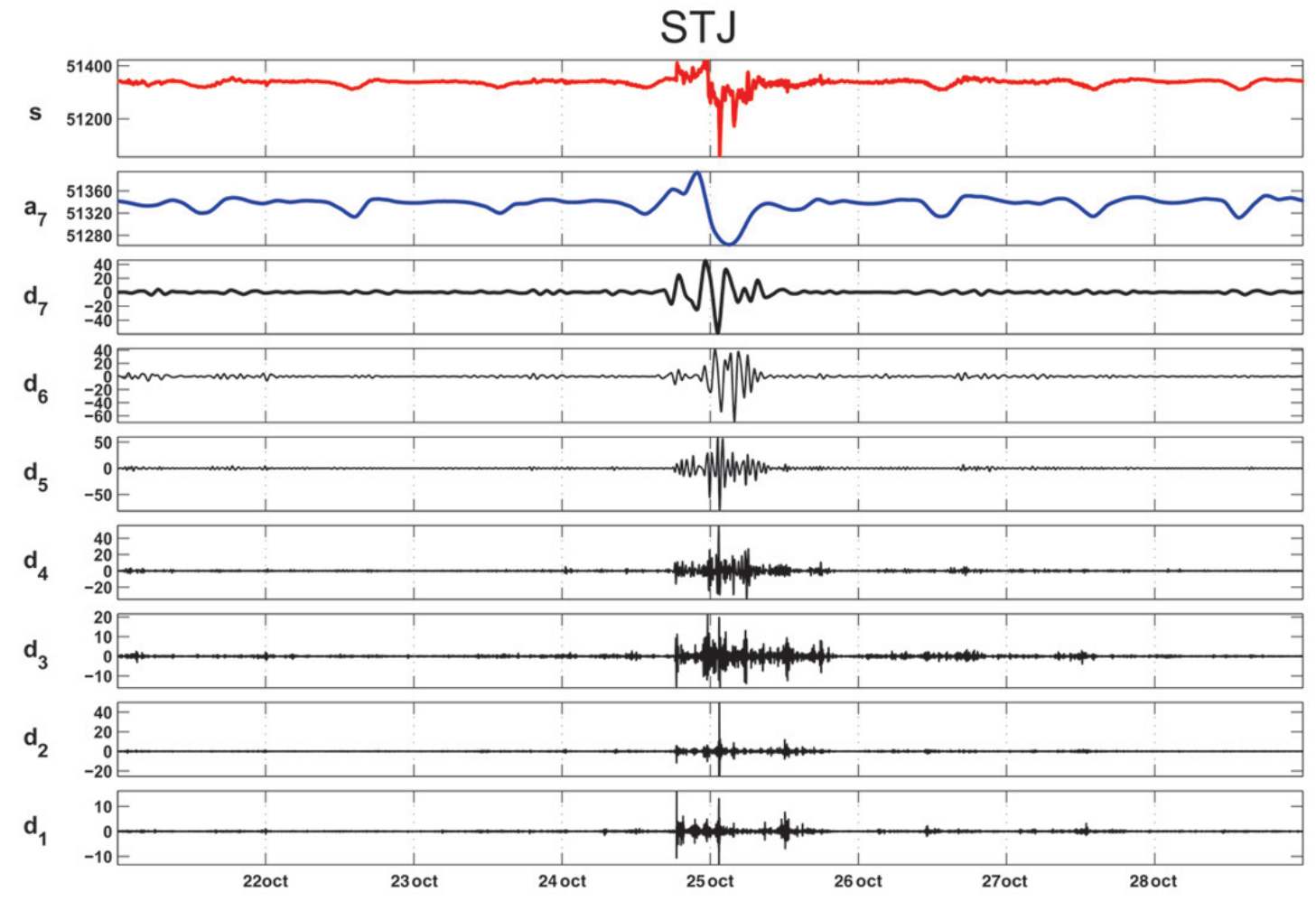

Figure 13 - Wavelet decomposition for observatory STJ data in the T1 magnetic storm period. 
$d_{4}$ to $d_{1}$ scales, on the 24th October. Noise in the PNL data was identified from $d_{3}$ up to $d_{1}$ scales. The wavelet decomposition for higher frequencies detect exactly the changes of trend occurring in the data in the beginning of the magnetic storm, providing the exact moment T1 started (05:15 pm on the 24th October in PNL station). The magnetic storm duration may also be obtained by wavelet analysis. In the PNL dataset $d_{4}$ appropriately limits the event that lasted 24 hours and 38 minutes.

The same analysis of starting and duration of $\mathrm{T} 1$ magnetic storm was performed for St John's (STJ) magnetic observatory (Fig. 13). This observatory was chosen due to its geographic location, nearer to the Auroral Electrojet, where magnetic disturbances of the same order of PNL station may occur. These results show that STJ observatory data were in accordance with the PNL station start and duration of T1 magnetic storm. In general, PNL data presented low noise and it is in conformity with the global beginning of the magnetic storm.

We used the decomposition $d_{4}$, as it adequately marked the beginning and the end of the magnetic storms in all analyzed observatories (Table 3). The beginning of the storms was marked as the moment the diurnal variation trend became disturbed, that is, when a peak appeared in the decomposition spectrum. The end of the magnetic storm was extracted from the data using the same criterium. Nevertheless in a different way, we registered the time when there were no more peaks in the spectrum. In PST, SJG and STJ magnetic observatories presented an unusual behaviour compared to the others.

Table 3 - Starting time and duration of the T1 magnetic storm occurred between 24th and 25th October 2011.

\begin{tabular}{|c|c|c|}
\hline $\begin{array}{c}\text { Observatory } \\
\text { (Acronym) }\end{array}$ & Beginning & Duration \\
\hline Pantanal (PNL) & $17: 51$ & 24 hours and 38 minutes \\
Ascension Island (ASC) & $17: 52$ & 24 hours and 35 minutes \\
Kakadu (KDU) & $17: 52$ & 24 hours and 53 minutes \\
Pamatai (PPT) & $17: 52$ & 24 hours and 36 minutes \\
Port Stanley (PST) & $17: 51$ & 26 hours and 20 minutes \\
San Juan (SJG) & $17: 52$ & 26 hours and 27 minutes \\
St John's (STJ) & $18: 08$ & 26 hours \\
\hline
\end{tabular}

The second magnetic storm T2 occurred between 21st and 24th January 2012. The T2 magnetic storm presented less intense values of the magnetic field and showed two typical beginnings. One occurred near the 22nd day and the other near the 24th day. We believe that this is the result of the impact of two distinct shock waves of solar wind that were generated from emissions of coronal mass by the sun, in two consecutive moments.

In T2 magnetic storm, PNL data presented a similar variability to the compared magnetic observatories. Whereas in PNL station the magnetic field presented a maximum variation of about $190 \mathrm{nT}$, in the other observatories (in similar latitudes) this range was about $160 \mathrm{nT}$ for ASC and $130 \mathrm{nT}$ for KDU and PPT. This magnetic storm showed a different behaviour from the T1 magnetic storm, presenting two storms in sequence with smaller intensity for the field variation than the first (Fig. 14).

The Dst index showed two instants of abrupt changes, one after the beginning of the 22nd day and the other in the first hours of the 24th day (Fig. 15). The $-69 n$ T lowest value for the index was reached in the first hours of the 23rd day. The Kp index also recorded the two peaks occurring during this storm. One of them was near the 23rd day and the other near the 25th day. The maximum Kp value occurred in the first three hours of the 23rd day, when $\mathrm{Kp}=5$.

The T2 magnetic storm was moderade, using as a parameter the Dst index, and weak according to Kp index. This small difference may be explained by the different observatories used for each index. In the T2 magnetic storm two peaks indicative of distinct shock waves were well marked (Fig. 16). The first abrupt change occurred at 05:50 am on 21st January and the second at 01:15 pm on the 23rd January in PNL station. These results were obtained by analysing the $d_{4}$ decomposition (Fig. 16), in which higher frequencies of the data were analyzed.

The $a_{7}$ wavelet level (low frequencies) registered the modulation produced by the magnetic storm. In the higher frequencies decomposition $\left(d_{7}\right.$ to $\left.d_{1}\right)$, the beginning of the two shock waves were clearly observed.

The STJ data were analyzed with wavelets and the agreement of the beginning of the two T2 shock waves with PNL data was confirmed (Fig. 17 and Table 4).

The first part of T2 magnetic storm occurred between 21st and 22nd January. In the second part of T2 magnetic storm it was not possible to evaluated the duration since there was not enough data. The first part of the T2 magnetic storm presented a regular behaviour of global beginning, but the second did not present the same characteristic.

During the occurrence of these storms, larger values of the wavelet coefficients were observed between wavelet levels 4 and 7 (Fig. 18). This analysis provides a panorama of the spectral variability the magnetic field presented during these storms and it can be used to compare different locations and/or different storm events. 

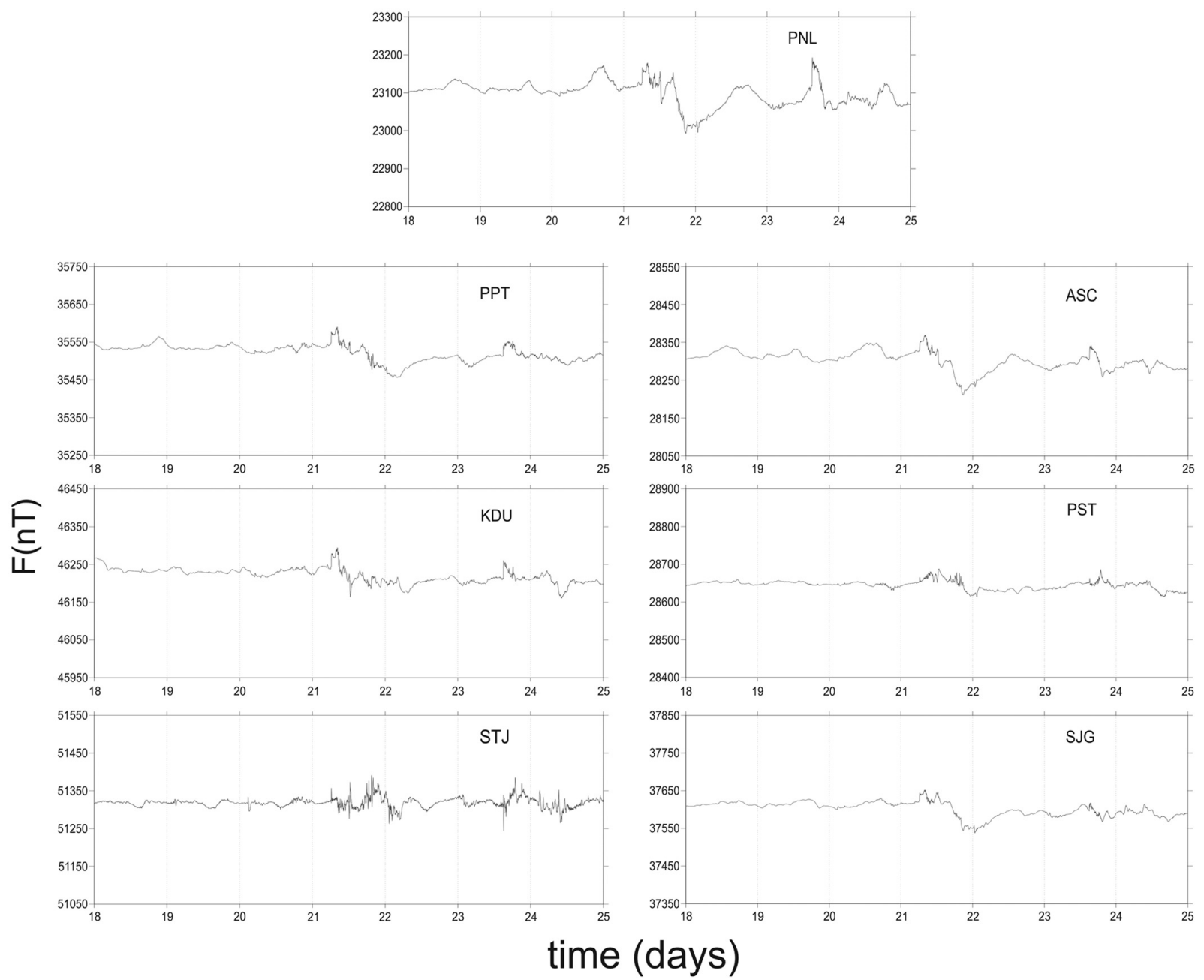

Figure 14 - T2 magnetic storm, between 21st and 24th January 2012, compared to observatories with latitudes (left column) and longitudes (right column) similar to Pantanal magnetic observatory.
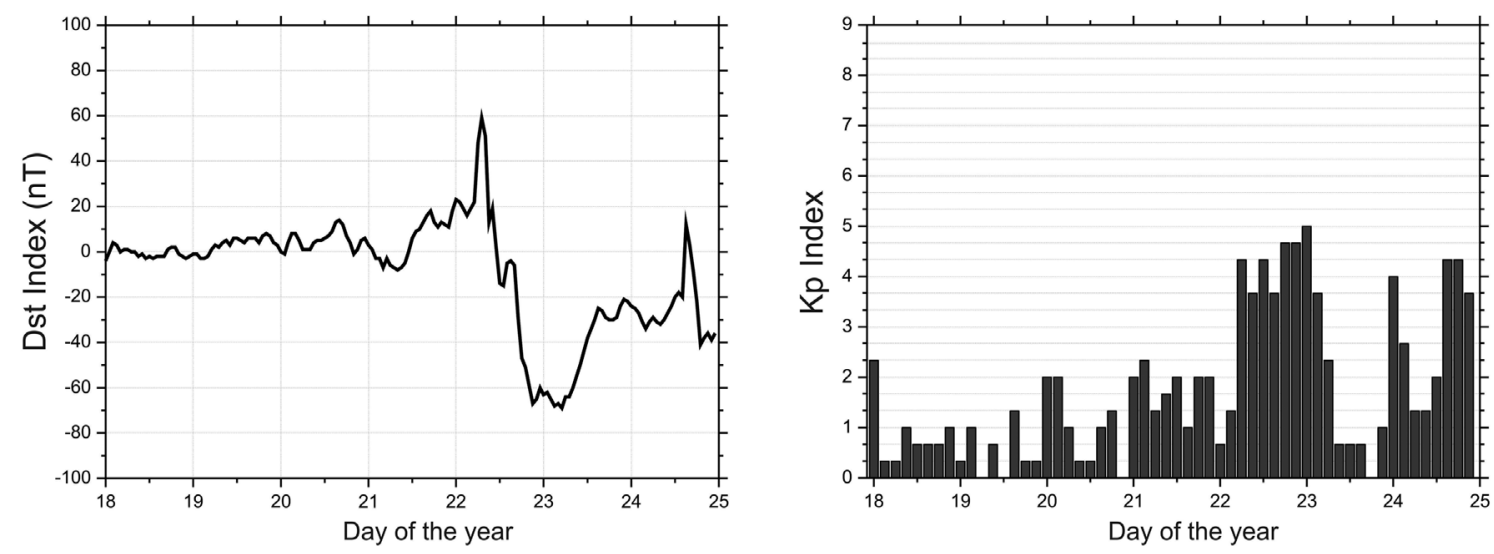

Figure 15 - Dst and Kp index variation during the T2 magnetic storm, between 21st and 24th January 2012. The left chart represents the Dst index (nT/time variation). The right chart shows the $\mathrm{Kp}$ index values during this magnetic storm. 


\section{PNL}

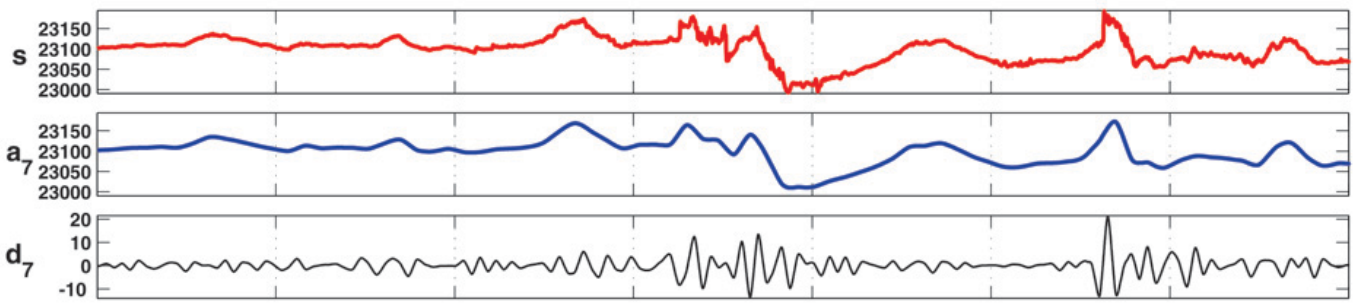

$d_{6}{ }_{-10}^{20} 0_{10}$
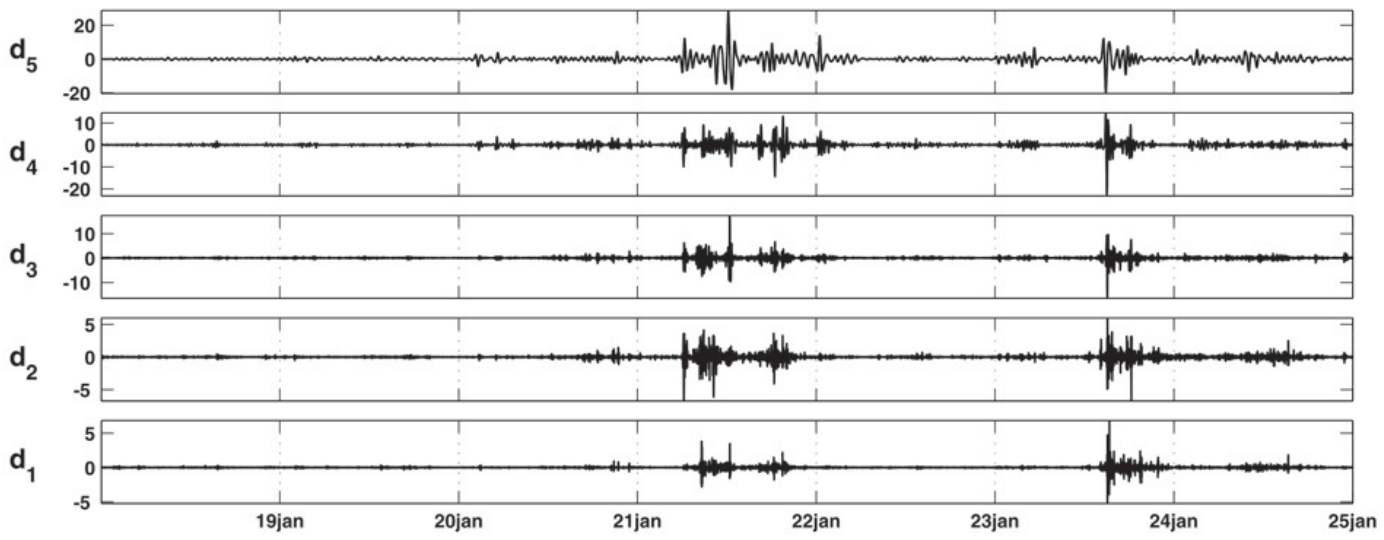

Figure 16 - Wavelet decomposition of data from the T2 magnetic storm measured in PNL.

\section{STJ}

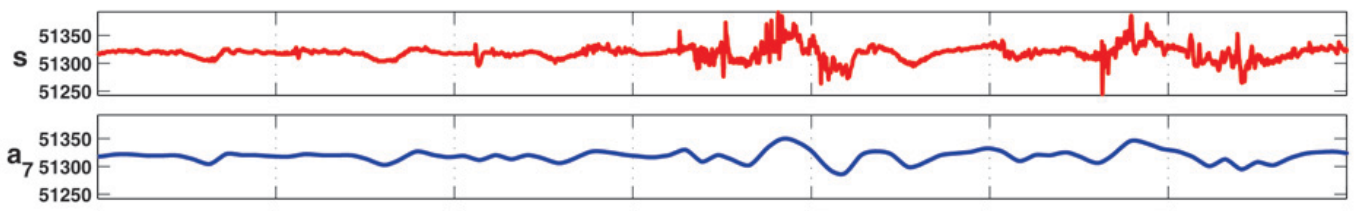

$c_{-20}^{10}$

d $_{6}$

$d_{5}=0$
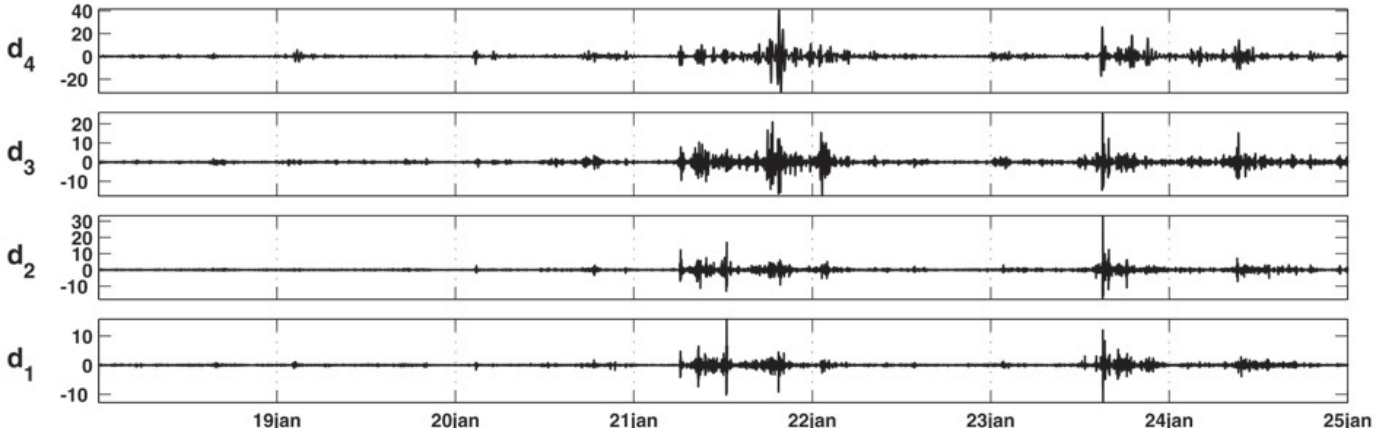

Figure 17 - Wavelet decomposition for STJ magnetic observatory data during the T2 magnetic storm. 
Table 4 - Starting hour and duration of the first part of the T1 magnetic storm which occurred between 21st and 22nd January 2012, and the starting hour of the second part of this storm on the 23rd January.

\begin{tabular}{|c|c|c|c|}
\hline $\begin{array}{c}\text { Observatory } \\
\text { (Acronym) }\end{array}$ & $\begin{array}{c}\text { Beginning } \\
\text { (1st part) }\end{array}$ & $\begin{array}{c}\text { Duration } \\
\text { (1st part) }\end{array}$ & $\begin{array}{c}\text { Beginning } \\
\text { (2nd part) }\end{array}$ \\
\hline Pantanal (PNL) & $05: 50$ & 22 hours and 18 minutes & $13: 15$ \\
Ascension Island (ASC) & $05: 51$ & 22 hours and 18 minutes & $13: 15$ \\
Kakadu (KDU) & $05: 51$ & 22 hours and 50 minutes & $13: 34$ \\
Pamatai (PPT) & $05: 51$ & 22 hours and 01 minute & $11: 15$ \\
Port Stanley (PST) & $05: 53$ & 22 hours and 07 minutes & $14: 37$ \\
San Juan (SJG) & $05: 52$ & 22 hours and 15 minutes & $14: 06$ \\
St John's (STJ) & $05: 56$ & 23 hours and 10 minutes & $14: 44$ \\
\hline
\end{tabular}

\section{PNL - T1}

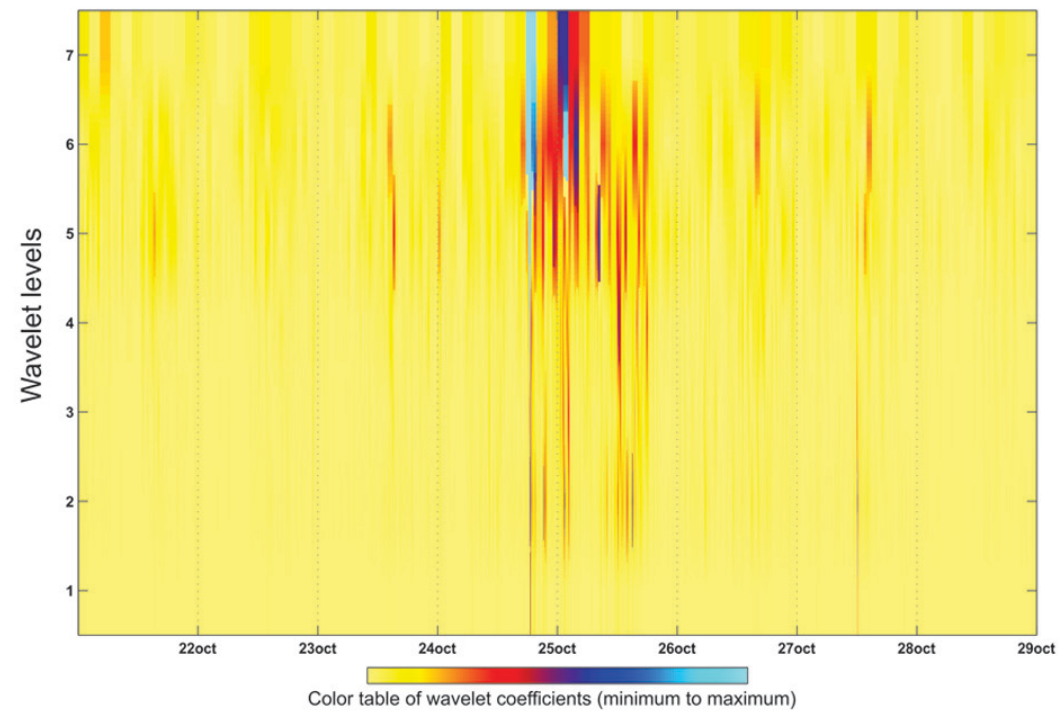

PNL - T2

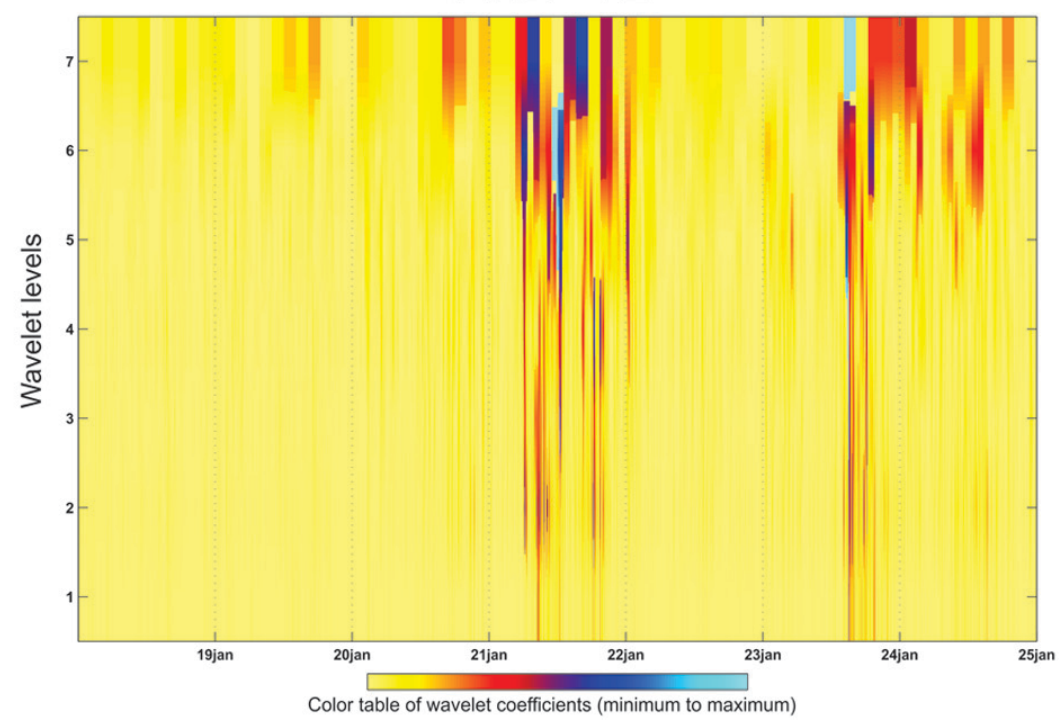

Figure 18 - Wavelet transforms of the PNL data for T1 and T2 magnetic storms. 


\section{CONCLUSION}

The Pantanal magnetic observatory site was properly chosen and during its construction all the materials were selected according to the tests. The observatory started its activities in October 2012.

The total field (F) measured in PNL was compared to other INTERMAGNET observatories demonstrating a good data quality in PNL. During these four months of observations, two magnetic storms occurred: between 24th and 25th October 2011 and between 21st and 24th January 2012. The behaviour of these magnetic storms was analyzed and compared for six magnetic observatories $\mathrm{A}$ wavelet data analysis was applied to filter the data and as result the beginning, duration and intensity of the two magnetic storms were detected. PNL data presented low noise and the range of the total magnetic field during the first magnetic storm was around $330 \mathrm{nT}$, while on average the other observatories it was of the order of $150 \mathrm{nT}$.

Geomagnetic field global modeling techniques and data analysis have improved considerably during the last decades. However the lack of data in critical regions, such as the SAMA and Equatorial Electrojet, disfavors a better understanding of these phenomena. Pantanal magnetic observatory will contribute to the acquisition and analysis of data on this important region for the study of the geomagnetic field.

\section{REFERENCES}

HARTMANN GA \& PACCA IG. 2009. Time evolution of the South Atlantic Magnetic Anomaly. An. Acad. Bras. Ciênc., 81(2): 243-255.

HEIRTZLER JR. 2002. The future of the South Atlantic anomaly and implications for radiation damage in space. Journal of Atmospheric and Solar-Terrestrial Physics, 64: 1701-1708.

JANKOWSKI J \& SUCKSDORFF C. 1996. IAGA Guide for Magnetic Measurements and Observatory Practice. International Association of Geomagnetism and Aeronomy. Warsaw, Poland, 235 pp.

MISITI M, MISITI Y, OPPENHEIM G \& POGGI J-M. 1997. Wavelet Toolbox User's Guide. MathWorks, 572 pp.

ROBERTS P. 2007. Theory of the Geodynamo. In: OLSON P (Ed.). Treatise on Geophysics. vol. 8, (Core dynamics). Elsevier, New York, pp. 245-282.

Recebido em 21 março, 2012 / Aceito em 1 dezembro, 2014

Received on March 21, 2012 / Accepted on December 1, 2014

\section{NOTES ABOUT THE AUTHORS}

Fillipe Siqueira. Bachelor degree in Physics at Universidade Federal Fluminense (UFF). Currently, is a doctoral student at the graduate program of Observatório Nacional (ON). Areas of interest: Geomagnetism and Geodynamo.

Katia Jasbinschek Pinheiro. Undergraduate in Oceanography at Universidade do Estado do Rio de Janeiro (2001), master degree in Geophysics at Observatório Nacional (2003) and doctorate degree in Geomagnetism at ETH Zurich (2004-2009). Was a contracted employee at Petrobras working with Environmental Geophysics (2002-2004). Since 2009 works as a researcher in geomagnetism at Observatório Nacional (MCT). Post-Doctorate research at Université de Nantes (LPGN) from 09/2013 to 08/2014. Experience in Geosciences with emphasis on Geomagnetism, mainly in the following themes: geomagnetic secular variation, magnetic observatories, magnetic data processing and modeling of electrical conductivity in the mantle. 